\title{
III INFORME ATR-VILLANUEVA. SEGUIMIENTO DEL CÓDIGO DE AUTORREGULACIÓN. HORARIO DE PROTECCIÓN REFORZADA DE LA INFANCIA
}

\section{ATR-VILLANUEVA III REPORT. TRACK SELF-REGULATION CODE. HOURS OF ENHANCED PROTECTION OF CHILDREN}

Maribel Martínez Eder: Portavoz de FIATYR (Federación Ibérica de Telespectadores y Radioyentes) mm.eder@asociacionplazadelcastillo.org

\section{CURRÍCULUM VITAE}

Fundadora y presidenta de la Asociación Plaza del Castillo ATR Navarra de Usuarios de Medios de Comunicación, integrante de FIATYR (Federación Ibérica de Asociaciones de Telespectadores y Radioyentes). Fue miembro del Consejo Asesor de RTVE en Navarra.

\section{RESUMEN}

En 2004 se firmó un acuerdo entre todas las cadenas de televisión con el fin de poner en marcha el Código de Autorregulación sobre contenidos televisivos e infancia. Ante una cierta demanda por parte de la sociedad por conocer hasta qué punto las cadenas de televisión estaban cumpliendo con dicho código, la Asociación de Telespectadores y Radioyentes comenzó una serie de análisis periódicos de la programación televisiva. En este texto se exponen los datos obtenidos a partir de estos trabajos de investigación que arrojan cifras tan demoledoras como que se han 
producido más de 700 incumplimientos referidos al lenguaje, la violencia o la ausencia de señalización, entre otros.

\section{PALABRAS CLAVE}

Cadena de televisión - Código de Autorregulación - Infancia - Programación Incumplimiento

\section{ABSTRACT}

In 2004 an agreement was signed between all the networks to implement the SelfRegulation Code on television content and children. Given a certain demand from society to know the extent to which broadcasters were complying with the code, the Viewers and Listeners Association began a series of periodic analysis of television programming. This text presents the data obtained from these research works as devastating as figures show that there have been over 700 violations relating to language, violence or lack of signage, among others.

\section{KEY WORDS}

Television - Self-Regulation Code - Children - Schedule - Breach

\section{ÍNDICE}

\section{Aclaración preliminar}

2. El Código de Autorregulación como manifestación de responsabilidad social de las cadenas de televisión

3. Objetivos de la investigación 


\section{Metodología}

5. Parrilla de programas. Escasa programación infantil

6. Datos de audiencia en la franja de protección reforzada (17:00 - 20:00)

7. Cifras de incumplimientos totales por cadenas

8. Incumplimientos por día

9. Primeros incumplimientos de La Sexta

10. Valoración de la web oficial del seguimiento del acuerdo tvinfancia.es

11. Valoración positiva del Decálogo de Buenas Prácticas Sobre Infancia y Contenidos Audiovisuales

12. Apoyo a la propuesta de creación del Consejo Audiovisual Nacional

13. Valoración positiva de las llamadas de atención del Defensor del Menor de la Comunidad Autónoma de Madrid y del Defensor del Pueblo

14. Limitaciones publicitarias en la franja infantil

15. Plan Estratégico Nacional de Infancia y Adolescencia 2006-2009

16. Necesidad de sanciones: Pantalla en negro

17. Comparación de los tres informes ATR-VILLANUEVA

18. Conclusiones

\section{TEXTO}

En el enlace les adjuntamos un informe elaborado por las Asociaciones de Telespectadores y Radioyentes (A.T.R.) en relación con el cumplimiento del Código de Autorregulación que firmaron los responsables de todas las cadenas de televisión en 2004. 
http://www2.uah.es/vivatacademia/ficheros/n77/IIIINFORMEATR-

VILLANUEVAjunio2006.pdf

Se contabilizan 736 incumplimientos referidos al lenguaje, violencia, sexo explícito, promoción, ausencia de señalización etc. 